\title{
Educación Social en y con la institución escolar
}

\author{
Artur Parcerisa Aran \\ UNIVERSIDAD DE BARCELONA
}

\section{Resumen}

La incorporación de profesionales de la educación social en los centros escolares es una muestra del dinamismo de la educación social, a la vez que lleva a replantear algunos conceptos. Este proceso puede colaborar a una mejor adecuación de la institución escolar o a reforzar una visión de la escuela que no es capaz de repensarse a sí misma, donde las y los educadores cumplen un rol que puede favorecer la segregación en lugar de la inclusión. Hay que avanzar mediante el trabajo colaborativo interprofesional, estableciendo puentes entre la cultura escolar y las formas y los recursos culturales de la comunidad.

PALABRAS CLAVE: Educación Social, Educación Formal, Inclusión, Comunidad, Fracaso Escolar, Diversidad.

\section{Summary}

The incorporation of Social Education professionals in the school center is a token of Social Education dinamism, what at the same time leads us to reconsider some concepts.
This process could contribute to improve the adaptation of the education institution or to reforce a view of the school that is not able to reconsider itself, where the educators play a role that could favour a segregation instead of an inclusion. It's needed to progress by a collaborative work between professionals, establishing connections between educational culture and the cultural resources and expressions of the comunity.

KEY WORDS: Social Education, Formal Education, Inclusion, Community, School Failure, Diversity.

\section{Introducción}

La progresiva incorporación de profesionales de la educación social en los centros escolares pretende ser una respuesta del Sistema a las dificultades de inserción escolar de una parte de la población infantil y adolescente. El proceso -lento, pero cada vez más extenso- de entrada de educadores y educadoras sociales en escuelas e institutos es una muestra del dinamismo de la educación social y de cómo cobran auge nuevos ámbitos de intervención de sus profesionales. 
La apuesta por convertir los centros escolares en territorios de acción de educadoras y educadores sociales supone replantear ciertos esquemas más o menos extendidos, puesto que en algunos momentos llegó a parecer que la profesionalización de la educación social se construía más en contraposición a lo escolar que como complemento o con lo escolar.

En todo caso, la presencia de las y los educadores sociales surge como respuesta a una problemática vivida por la escuela, la cual en ocasiones se ve incapaz por sí sola de gestionar las dificultades de convivencia que se dan en su seno y, en el mejor de los casos, encuentra límites normativos y de concepción cuando pretende extender su acción más allá del entorno escolar.

Esta respuesta, a la que rápidamente se han acogido los colegios y otras instituciones profesionales de educación social, tiene potencialidades, pero también riesgos. En esta primera etapa de entrada en los centros escolares de las y los educadores sociales se juega gran parte de lo que puede ser en el futuro el papel de estos profesionales en la institución escolar, pero también, -y ello es más relevante- el papel de la pedagogía social en la escuela e incluso de la propia escuela como institución social.

En esta relación entre la más importante institución educativa de la infancia y la adolescencia -junto con la familia-, y aquellos que se ocupan específicamente de la educación social se abren importantes expectativas en el sentido de reconfigurar el concepto tradicional de escuela y de darle una dimensión más acorde con las necesidades y las características de la sociedad actual, pero a la vez se corre el riesgo de no aprovechar la oportunidad y afianzar un sentido de institución escolar que no responda adecuadamente a los requerimientos sociales.

Ello sería así si en escuelas e institutos se mantuviera un sistema de funcionamiento y de organización y unas pautas de acción que no tuvieran en cuenta que hoy día la sociedad cambia a un ritmo muy acelerado y si se olvidara que la institución escolar tiene que compaginar su tarea educativa con otras fuentes formativas y que tiene la obligación de atender y ayudar a la formación de toda la población infantil y adolescente. Ante una realidad nueva, no se puede dar una respuesta adecuada con una concepción de escuela pensada para otra realidad histórica.

\section{Dinamismo en el concepto de educación social: nuevos ámbitos de intervención}

No hace demasiados años, Trilla (1996, 41 y s.s.) ${ }^{1}$, en un texto en aquel momento muy clarificador sobre el concepto de educación social, consideraba que existían tres concepciones que podían considerarse claras y, a la vez, de uso extendido. Se trataba de conceptos "esencialistas", ya que cada uno de ellos definía la característica que debía compartir todo aquello que formaba parte de la educación social.

Las tres concepciones eran las siguientes: la educación social como aquella educación que tiene por objetivo desarrollar la socialización de la persona; la educación social como la educación que tiene como destinatarias a personas en situación de conflicto social; la educación social como educación no formal (que puede equipararse a educación en contextos educativos no escolares).

El propio Trilla critica las tres concepciones, ya que, para él, ninguna de ellas permite determinar qué es lo esencial en pedagogía social. Propone considerar como objeto de la pedagogía social la educación que, como mínimo, reúna dos de las concepciones expuestas.

Con esta propuesta se hablaría de educación social cuando se tratase de una educación que tuviera como objetivo la socialización y se dirigiera a personas en situación de conflicto social; o de una educación con el 
objetivo de la socialización en un ámbito no formal; o de una educación no formal dirigida a personas en situación de conflicto social. Se observa que en dos de los tres casos posibles se está haciendo referencia a la educación no formal.

En aquellos momentos, tal como señala Petrus $(1996,29)$, a menudo se recurría a la definición de la educación social por negación, determinando el espacio de intervención de la educación social por exclusión: la educación social comprendía cualquier intervención educativa estructurada que no fuese escolar.

En un texto que publiqué en 1999 (pp. 18) consideraba la educación social como "el conjunto de procesos formativos no formales que tienen como sujetos prioritariamente a personas y colectivos en situación de conflicto social y a colectivos con riesgo de encontrarse en esta situación". Creo que la definición sigue siendo válida, pero habría que matizar el concepto de procesos formativos no formales y, quizá, incluso fuera preferible obviar este término que, si bien en un momento determinado sirvió para ayudar a caracterizar un espacio profesional nuevo, en la realidad actual puede crear más confusionismo que claridad.

En este sentido, Ortega $(2005,168)$ señala que hablar de educación no formal o informal es semánticamente contradictorio: "Si algo es educación, es formal; si es no formal o es informal, no es educación". El título del artículo donde recoge la anterior afirmación es elocuente: "La educación a lo largo de la vida: la educación social, la educación escolar, la educación continua... todas son educaciones formales".

Ante la realidad actual creo que es preferible obviar el concepto de "no formal" referido a la educación social y optar por definiciones -siempre provisionales- que reflejen su dinamismo y su capacidad de dar respuesta a las nuevas necesidades sociales.

Una de las definiciones más recientes que responden a estas premisas es la de Giné
(2007, 68): para esta autora, la educación social puede entenderse como

"un proceso de desarrollo integral y promocionador de las personas, mediado por la función pedagógica intencional y posibilitadora, desarrollada por profesionales, y presente en múltiples ámbitos con la finalidad de procurar, favorecer y potenciar la adquisición de bienes culturales, que amplíen las perspectivas educativas, laborales, de ocio y participación social, y posibiliten la incorporación activa y transformadora de estas personas a un contexto social y cultural concreto".

Las anteriores consideraciones cobran plena actualidad cuando la evolución de la dinámica social hace aparecer nuevos retos a los que deben dar respuesta las políticas sociales, incluyendo las políticas de intervención educativa, y cuando específicamente ello lleva a plantear la entrada de educadores y educadoras sociales en los centros escolares, es decir: en el ámbito considerado de educación formal en los textos que utilizan esta terminología.

Las nuevas realidades sociales han hecho surgir o han incrementado la necesidad de apoyo a estructuras familiares nuevas, de políticas y estrategias que ayuden a la inclusión de la emigración, de políticas inclusivas de la discapacidad, de atención a la realidad de gente mayor activa y a la de gente mayor dependiente... Estas problemáticas requieren de intervenciones desde distintas ramas profesionales (salud, asistencia social, arquitectura, etc.), pero la intervención educativa es indispensable para que sea posible un cambio real que, como mínimo, aminore las problemáticas.

La educación social tiene como característica su preocupación por responder a las nuevas demandas sociales y precisamente, tal como apunta Riera $(1998,43)$, en ello estriba la principal dificultad para llegar a un acuerdo estable sobre la definición de educación social: "en el hecho de que este con- 
cepto va ligado al contexto social, la concepción política, las formas de cultura predominante, la situación económica y la realidad educativa de un momento determinado".

En el mismo sentido, Caride $(2005,54)$ señala que la educación social se caracteriza por ser una práctica sujeta a los avatares que afectan a un amplio repertorio de variables políticas, económicas, culturales y pedagógicas "en las que se configuran y sostienen sus diferentes realizaciones". Probablemente este dinamismo sea una de las explicaciones a la "pluralidad de concepciones existentes en relación a las funciones, a los ámbitos, a los espacios en los que interviene la Educación Social" que señala March $(2007,41)$.

Así pues, ante la necesidad de responder a nuevas realidades sociales, la educación social atiende actualmente a ámbitos en los que hasta ahora había intervenido poco ${ }^{2}$. Entre estos: la institución escolar.

\subsection{Nuevos ámbitos de intervención en educa- ción social: la institución escolar}

La relación entre educación social y educación no escolar había llegado a ser casi indiscutible, hasta el punto de que en ocasiones se asistía a una formación de los futuros educadores y educadoras sociales que parecía ir más contra la escuela -en el sentido de afirmar la nueva profesión como una superación de las deficiencias de la educación escolar- que con la escuela, en el sentido de acción educativa complementaria.

Independientemente del error que podía suponer este proceder -más o menos presente en algunas aulas universitarias- lo cierto es que en los últimos años hemos asistido a un progresivo cambio conceptual, a tenor de la evolución de la sociedad y de la manifestación de sus nuevas necesidades.

Petrus (2000, 79-80), ante el progresivo incremento de los escolares que no se adaptan a las exigencias de la cultura escolar, señala que la educación social deberá prestar cada vez más atención a esta problemática escolar, abriéndose a la sociedad y a sus problemas, sin "protegerse en el noble objetivo de los contenidos instructivos". La institución escolar ha de preocuparse también de la educación social: en la escuela "se ha de hablar, si es preciso, de las emociones, de los conflictos sociales, de la televisión, de la marginación, de la violencia, de las tribus urbanas, de la droga y de los skins".

Hoy día, según Petrus, la educadora y el educador social tienen un papel a jugar en la institución escolar en tanto que "la escuela no es capaz, por sí misma, de solucionar los complejos problemas de la población infantil y juvenil, como tampoco puede resolver las dificultades de la institución familiar".

Cuando se habla de educación social se suele producir una confusión entre lo que podemos denominar la vertiente social de toda educación y las tareas que profesionalmente se han asignado a los denominados educadores y educadoras sociales. En este sentido Riera (1998, 51-52) manifiesta que "la vinculación de la educación social a espacios considerados extraescolares o paraescolares o de soporte o no escolares no es correcta. No es plausible relacionar con la educación social sólo aquel ámbito educativo que se desmarca del sistema reglado".

Para Riera, el profesorado realiza una tarea importantísima de educación social: se hace educación social dentro del aula, y en este sentido "sería procedente revisar el grado de relación, interacción, que estos agentes establecen durante su intervención educativa, con el entorno" para que ello ayudara a emplear todos los recursos socioculturales o a crear nuevas alternativas. La otra cara de la moneda -apunta Riera- es que los profesionales de la educación no formal deberían revisar el grado de relación e interacción que ellos establecen con el entorno formal.

Según este autor, limitar el término educador social a un espacio profesional determinado no ha ayudado a clarificar el con- 
cepto de educación social, lo cual no significa que no sea claramente defendible el perfil propio de los diplomados en educación social. En todo caso, se hace imprescindible la colaboración interprofesional en entornos formales, aportando cada uno su especificidad.

En el mismo sentido se han manifestado otros autores, como Pérez Serrano (2003, 136), para quién "la educación social tampoco puede definirse por ocupar el espacio no escolar, dado que implicaría una reducción de la misma". Para esta autora, la educación social aparece en la educación escolar a través de los temas transversales, de los programas de educación de personas adultas, de los programas de garantía social, de la formación sociolaboral, la educación compensatoria, etc.

La complejidad de las necesidades sociales y educativas actuales, así como de las respuestas posibles ante estas necesidades, requiere que la educación social sea capaz de adecuarse a estas necesidades y que encuentre su sitio en el abanico de respuestas posibles. Ello significa que debe irse reconceptualizando, en un proceso de construcción y reconstrucción de su papel social y de sus ámbitos de intervención. La alta capacidad de adecuación de la educación social a necesidades sociales emergentes es uno de sus valores principales aunque ello necesariamente suponga que afloren contradicciones y dudas que, sin pretender simplificaciones imposibles, deben servir de estímulo para ayudar a que la educación social cumpla sus funciones sociales.

\section{La perspectiva desde la institución escolar}

La institución escolar afronta la dificultad que supone tener que adecuar a nuevas realidades sociales una institución de prestigio bien adaptada a un modelo de sociedad industrial, mucho más estable que la actual, donde las tecnologías de la información y la comunicación eran incipientes, y donde la escuela ocupaba el centro del saber sin apenas otras fuentes que pudieran hacerle "competencia".

A todo lo anterior hay que añadir que el logro social que en las sociedades desarrolladas ha supuesto la escolarización obligatoria de toda la población infantil y adolescente ha comportado que la escuela tiene que acoger, inserir y atender adecuadamente a una gran diversidad de alumnado, una parte del cual no sintoniza con facilidad con las pautas culturales predominantes en la institución escolar.

La posibilidad de acoger a toda la población infantil y adolescente convierte la escuela en la institución potencialmente con más incidencia en la educación de la ciudadanía de un país. Pero esta potencialidad supone un reto nuevo para la institución escolar, que pasa de acoger a una parte escogida de la sociedad a tener que responder a las necesidades y nuevas situaciones creadas por la escolarización obligatoria.

La institución escolar afronta pues un doble desafío: adecuarse a las características de la sociedad del conocimiento y de las tecnologías, de la globalización y del multiculturalismo... y responder adecuadamente a una diversidad cada vez mayor de su alumnado. Ello no es fácil y, en todo caso, requiere de un proceso de aprendizaje por parte del propio sistema escolar.

En este proceso de aprendizaje de la propia escuela se requieren recursos y ayuda. La escuela tiene que afrontar diversas situaciones problemáticas, complejas y simultáneas: desde el rechazo de la institución escolar por parte de algunos alumnos y alumnas -incluso con el desarrollo de mecanismos de autoprotección contra el aprendizaje escolar que llevan a desaprender lo aprendido- hasta las dificultades de convivencia surgidas por la imposición de pautas de comportamiento -herencia de una escuela pensada para otra 
sociedad y para otro tipo de estudiantesante las cuales una parte de la población escolar genera respuestas disruptivas.

El panorama aún es más complejo puesto que, como apunta Morgenstern (1995, 334), la salida tradicional para el colectivo que fracasaba en el sistema escolar era la incorporación temprana al mercado laboral, pero, ante la precariedad actual de éste, muchos jóvenes se encuentran abandonados por el sistema educativo y marginados por el mercado de trabajo.

La escuela tiene un problema, y las continuadas reformas que se suceden en los países occidentales no lo resuelven y, en cierta medida, incluso lo agravan, puesto que se crea una sensación de inseguridad y de transitoriedad -la misma transitoriedad que caracteriza a la sociedad occidental actual en su conjunto- que dificulta que la institución escolar pueda disponer de unos referentes sólidos donde asirse y de un ambiente suficientemente sereno para analizar la situación y formular propuestas de acción.

El profesorado, ante esta situación -donde constantemente se habla de la crisis de la escuela- a menudo se encuentra desconcertado, con cierta sensación de soledad $y$, en ocasiones, con la idea de que lo que se predica en la escuela va contra lo que se vive fuera de ella. Lo cierto es que la institución escolar necesita cambios profundos, como no podría ser de otra manera en una sociedad que ha cambiado -y está cambiandomucho.

En algunos centros, el profesorado no se ve capaz, por sí solo, de dar respuesta a la multiproblematización con la que se encuentra, y ello genera expectativas negativas y sensación de desánimo a una parte de este profesorado. Probablemente, en general no se está haciendo tan mal como suelen reflejar, de tanto en tanto, los medios de comunicación, pero se va instalando una sensación negativa que no facilita la serenidad y la motivación necesarias para ir avanzando hacia el replanteamiento del modelo de escuela.

Las soluciones no son fáciles, como no lo son nunca ante situaciones muy complejas. Y, en todo caso, seguro que no pueden ser reduccionistas -más disciplina, más autoridad...- si aspiran a ir al fondo de la cuestión. La institución escolar tiene un problema, y para su solución se requiere, entre otras cosas, de un papel activo por parte del profesorado ante él y de explorar lazos de relación entre la escuela y el entorno. La presencia de los educadores y las educadoras sociales en los centros intenta ser una primera respuesta.

\section{La incorporación de educadores y educadoras sociales en los centros escolares: una oportunidad que exige una construcción colectiva}

El año 2004, los colegios profesionales de educadores sociales hicieron público un documento titulado "El educador y la educadora social en el Estado español: una concreción de su trabajo en centros escolares". Este documento respondía a una realidad: en diversas zonas de España se empezaba a introducir al educador social en escuelas y en institutos de educación secundaria.

\subsection{Una aproximación al estado de la cuestión}

Aunque el proceso que institucionaliza la figura del educador y de la educadora social en los centros escolares es pausado, lo cierto es que se trata de un hecho que se está desarrollando, a distintos niveles, en diversas comunidades autónomas del Estado español. Las pioneras fueron Castilla-La Mancha y Extremadura.

Una Orden de 26 de junio de 2002 de la Consejería de Educación y Cultura de Castilla-La Mancha establece que se dotará a los centros que lo justifiquen suficientemen- 
te "por la problemática de convivencia, de un educador social para que actuando de forma coordinada con el tutor y el orientador desarrolle tareas de mediación y control en colaboración con las familias y con otras instituciones. Asimismo, desarrollará medidas para asegurar la asistencia regular del alumnado a las clases, actuando en aquellas situaciones de alto riesgo con acciones positivas de control y prevención del absentismo escolar".

En unas Instrucciones posteriores, de 1 de septiembre de 2003, de la Dirección General de Coordinación y Enseñanzas Universitarias de esta comunidad autónoma, al definir el plan de actuación de los educadores y las educadoras sociales en los institutos de educación secundaria, se pone énfasis en el desarrollo de tres programas: atención al absentismo, promoción de la convivencia y animación sociocultural.

También en unas Instrucciones de la Dirección General de Ordenación, Renovación y Centros de la Junta de Extremadura, de octubre de 2002, se establecen las funciones y ámbitos de actuación de los educadores sociales en centros de educación secundaria de la red pública. La introducción de estos educadores se justifica, en primer lugar, "en la constatación de que dichos centros, como reflejo de la sociedad actual, presentan una realidad cada vez más compleja, y las situaciones problemáticas que en ellos pueden darse necesitan de personas que las conozcan en profundidad y que por su formación específica puedan ayudar a prevenirlas y buscar soluciones en colaboración con los restantes miembros de la comunidad educativa".

Estos dos ejemplos sirven para obtener una primera idea respecto de la justificación de la incorporación a los centros escolares de los profesionales de la educación social y sobre las funciones que se les atribuyen.

Existen otras experiencias institucionales de introducción de educadores y educadoras sociales en los centros escolares. Veamos algunos ejemplos más ${ }^{3}$.
En Zaragoza, el curso 1990-91, empezó a implantarse el Proyecto de Integración de Espacios Escolares (PIEE) con el desarrollo de un trabajo de intervención socioeducativa en alumnado con dificultades de integración social. La intervención socioeducativa en la institución escolar se produce cuando en el contexto se dan determinadas características: alto índice de fracaso escolar, absentismo, descenso continuado de matrícula, capas amplias de chicos y chicas en situación de riesgo, altas tasas de inmigración, etc.

En Euskadi se desarrollan experiencias de comunidades de aprendizaje ${ }^{4}$-también presentes en otras comunidades- donde se parte del principio de que todos los niños y niñas tienen derecho a una educación que no les condene desde su infancia a no completar el bachillerato y a no acceder a un puesto de trabajo. En las comunidades, la participación del educador social se considera algo natural.

En las islas Baleares, la figura del educador social, contratado por ayuntamientos con convenio con la Consejería de Educación, se encuentra en aulas externas de los centros escolares de diversos municipios, y en Ibiza se contrata a educadores sociales para trabajar en programas específicos dentro del ámbito escolar.

En Galicia, en 1998 se inició el proyecto Dorna: Embárcate Na Saúde, consistente en la implantación de un equipo de educadores y educadoras sociales dentro de un centro educativo de secundaria. Se trató de una propuesta de trabajo preventivo dirigida a la promoción de la salud, entendida desde una visión integral.

En Catalunya, desde 1985 se dan procesos formalizados de trabajo entre la administración educativa y los servicios sociales de atención primaria de los ayuntamientos.

La relación anterior, que podría completarse con distintas experiencias municipales y que probablemente podría actualizarse con nuevas experiencias, es una muestra 
suficientemente elocuente de cómo los profesionales de la educación social van entrando en los centros escolares. Este proceso explica que los colegios profesionales presentaran el documento al que anteriormente he hecho referencia.

Este documento propone una relación amplia de funciones para las y los educadores sociales en centros escolares, que giran alrededor de la elaboración, la implementación, la colaboración y la evaluación de:

- Programas de convivencia.

- Normativas del centro.

- Propuestas para fomentar las relaciones del centro con su entorno social.

- Programas transversales (educación para la salud, medio ambiente, etc.).

- Programas de interrelación con la comunidad y de aprovechamiento y conocimiento de los recursos del entorno.

- Creación de espacios y de equipos de trabajo mediadores y negociadores para la eficacia en la resolución de conflictos.

- Seguimiento y control de las situaciones de absentismo escolar, fracaso y violencia.

- Seguimiento y colaboración en la respuesta educativa al alumno con comportamientos problemáticos.

- Programas para prevenir y afrontar la conflictividad escolar.

- Actividades complementarias y extraescolares.

- Actuaciones encaminadas a garantizar la información puntual a las familias sobre el proceso educativo de sus hijos.

- Programas de información, orientación, asesoramiento y asociación dirigidos al alumnado, y otros dirigidos a las asociaciones de padres y madres.

- Apoyo a la formación del profesorado.

Desde mi punto de vista, se ha pretendido hacer una relación extensa, donde no quedase fuera nada de lo que un educador social puede realizar en una escuela o instituto. Como tal relación, sirve para mostrar que los profesio- nales de la educación social pueden tener un papel en los centros escolares, pero ayuda poco a definir su rol y a concretar sus funciones en un contexto determinado. Se ha optado por una relación amplia en lugar de por la focalización en algunas funciones determinadas especialmente relevantes, pero probablemente ello obedece a la propia diversidad y flexibilidad de la profesión.

\subsection{Oportunidades y riesgos}

La incorporación de educadores y educadoras sociales supone la oportunidad de romper cierto aislamiento de muchos centros escolares, de introducir en la escuela una visión más amplia de educación y una concepción más integral de la realidad del niño, la niña o el adolescente, que incluya su entramado social. Supone también una buena oportunidad para trabajar y reflexionar sobre la función integradora de la institución escolar.

Asimismo, puede ayudar a introducir en el centro escolar maneras de enfocar las situaciones educativas y las secuencias formativas características de la educación social que pueden complementar las estrategias tradicionalmente más académicas 5 .

Educadores y educadoras pueden compartir con el profesorado la idea de la educación como proceso -y no sólo como resultado-, la importancia de la negociación o el acuerdo entre educando y educador, la idea del trabajo a partir de las potencialidades -más que de los déficits o las dificultades-, la de aproximación ecosistémica o la de flexibilidad y adaptabilidad.

Todas estas posibilidades que se abren con la entrada de la nueva figura profesional en las escuelas e institutos corren el riesgo de quedar en nada si se cae en la reproducción de hábitos que suelen darse, a menudo, en la colaboración con otros profesionales desde el profesorado (por ejemplo, con asesores psicopedagógicos). 
Hay que rechazar el enfoque clínico y adoptar una perspectiva global y colaborativa. Como señala Cabrera $(2004,10)$, hay que optar por la colaboración en lugar de hacerlo por un modelo "de experto".

El trabajo en colaboración entre los profesionales de la educación social y los de la docencia escolar debe irse construyendo paso a paso, ya que de entrada presenta algunas dificultades. Hay que tener muy clara la importancia de una cultura de colaboración interprofesional para que valga la pena el esfuerzo que supone partir de dos culturas profesionales distintas.

De entrada, probablemente el profesorado le pedirá al educador o educadora social que dé respuestas urgentes a los problemas, pero es precisamente en la construcción de un trabajo en equipo donde debe irse fraguando una línea de actuación compartida que tenga en cuenta que toda intervención educativa requiere de procesos de acción prolongados.

En este sentido, hay que prestar mucha atención al análisis de hasta qué punto las intervenciones favorecen la inclusión y hasta qué punto se convierten de facto en segregadoras. Gasch (2006, 65), analizando las Unidades Escolares Compartidas (UEC) de Catalunya, señala que "se ha podido entrar en una dinámica de exclusión muy peligrosa, más allá de estar en el espacio escuela o fuera del espacio escuela". Para esta autora, el adolescente que es derivado a una UEC "es objeto de dinámicas de intervención fundamentadas en la criminalización y la patología de sus conductas".

La intervención del educador o educadora social puede ser directa, en situaciones interactivas con el educando, pero también puede ser indirecta, interviniendo en el diseño de medios, programas o situaciones potencialmente educativos conjuntamente con el profesorado.

En el Código deontológico del educador y la educadora social, elaborado por la
Asociación Estatal de Educación Social, en 2004, se señala que la práctica diaria de los educadores y de las educadoras sociales se articula alrededor de tres tipos de actuaciones:

"1. Actuaciones de contexto, aquellas acciones y tareas que se dirigen a posibilitar un contexto educativo o a mejorarlo o a dotarlo de recursos.

2. Actuaciones de mediación, entendida como 'estar entre'. Como el trabajo que el educador realiza para que el sujeto pueda encontrarse con lugares, personas y contenidos en su dimensión social, cultural y relacional.

3. Actuaciones formativas e instructivas con personas o grupos. Aquellas que posibiliten la apropiación de elementos culturales por parte del sujeto. Actos de enseñanza de herramientas conceptuales, habilidades técnicas o formas de trato social. En el ámbito escolar esta tipología también resulta útil”.

En todo caso, el proceso de trabajo conjunto tiene que ayudar a construir un concepto de intervención educativa. Ésta puede entenderse como una acción intencional, que debe tener como finalidad general el desarrollo personal y social de las personas, grupos y comunidades, mejorando su calidad de vida e incidiendo positivamente en su participación en la sociedad (Pallisera, 1996, 8). Pero una conceptualización como la descrita quizá no sea fácil de asumir, de entrada, desde la escuela o el instituto.

Se requiere, por tanto, trabajar sobre el tema, lo cual va muy ligado a reflexionar sobre el modelo educativo de la institución.

En una perspectiva crítica, la intervención educativa tiene que partir de la realidad y de las particularidades de los sujetos y grupos. Es en los individuos y en los grupos -tal como apunta Freire (1970, 131) - donde existen los temas, los problemas, la realidad percibida y sentida por ellos y que ha de ser reconstruida. 
Tal como señala Schön (1983), la práctica es problemática y sus situaciones resultan a menudo confusas y engañosas. A través de la reflexión, el práctico (docente o/y educador social) saca a la luz el conocimiento implícito y tácito en la acción, que es entonces integrado con ésta y con su resultado. La tentativa de entender una situación a través de la acción conduce a unos cambios en la situación, cambios que en sí mismos generan nuevas comprensiones y una acción renovada. Compartir interprofesionalmente este proceso puede ser muy enriquecedor, pero no es sencillo.

Por otra parte, el trabajo conjunto entre profesionales debe proporcionar una visión amplia, integral y sistémica de los educandos y educandas. Éstos y éstas viven en la escuela y fuera de la escuela: en la familia, en la pandilla, en la calle... Segmentar esta realidad, olvidándose o negando una parte de ella, no permite ni un diagnóstico adecuado ni una intervención acertada. La escuela no puede encerrarse en sí misma. La incorporación de profesionales externos puede ser una buena oportunidad para avanzar en esta línea.

Molina y Blázquez (2006, 40) apuntan que la introducción de educadores y educadoras sociales en los centros escolares no debería limitarse a solucionar problemas que el profesorado no puede afrontar por sí solo, sino que "puede ofrecer nuevas posibilidades al sistema en su conjunto", puesto que el educador social "traza puentes entre la cultura escolar y las formas culturales de las comunidades y territorios en los cuales se ubican los centros". Esta vertiente probablemente es la que mejor puede diferenciar al educador o la educadora social de otros profesionales que colaboran con el profesorado.

Para que las oportunidades no se conviertan en dificultades insalvables, tanto desde la escuela como desde la educación social hay que plantearse el porqué, el contenido y el cómo de la relación. Desde la educación social hay que esforzarse especialmente, ya que se trata de entrar en territorio ajeno, para llegar a construir un territorio compartido.

El educador y la educadora social tienen que ayudar al profesorado, pero deben cuidar de que se establezca una relación y una creación de vínculos que partan de un trabajo colaborativo, de una preocupación común. Ello en muchas ocasiones no será fácil, pero es algo esencial para que la incorporación de educadores y educadoras sociales en los centros pueda constituir una respuesta adecuada a los retos con los que se enfrenta la escuela actual.

Un vínculo sustentado en el marco del trabajo colaborativo entre profesorado y educadores sociales puede, a su vez, posibilitar dar un paso más: la ubicación de esta relación en un contexto más amplio, el de la acción comunitaria.

\subsection{La acción comunitaria como alternativa}

La emergencia de la globalización, la fragmentación, la exclusión, la desafiliación social (Castel, 1991) y los procesos de individualización que caracterizan a nuestra sociedad provocan una reacción, en defensa de las propias identidades colectivas, que, según Llena y Úcar $(2006,13)$, provoca una "vuelta a la comunidad o a lo comunitario".

Aunque existe una gran disparidad terminológica y conceptual, creo que por acción comunitaria puede entenderse el desarrollo de procesos que pretenden y llevan a cabo, en grado diverso, transformaciones de situaciones colectivas mediante la organización y la acción asociativa.

La acción comunitaria consiste en la constitución y el desarrollo de grupos sociales que trabajen para elaborar y aplicar proyectos de desarrollo social que se enmarquen en un contexto de desarrollo de redes sociales.

Una sociedad global y compleja como la actual requiere una educación integrada y 
transversal, con participación de agentes y recursos diversos. La institución escolar tiene -como se ha dicho- un papel especialmente relevante, pero no lo puede desarrollar al margen de los otros agentes y recursos.

Los profesionales de la educación social pueden colaborar a esta apertura del centro y, quizá, a que se avance hacia planteamientos comunitarios, en los cuales la propia comunidad es agente educador y, a la vez, sujeto educando. Se trata de una apuesta por la corresponsabilidad educativa de la comunidad.

El educador y la educadora social pueden ayudar a poner en marcha grupos, procesos y redes de acción comunitaria, con la participación de la institución escolar, colaborando así a que se unan esfuerzos para afrontar problemáticas complejas (fracaso escolar, problemas familiares, dificultades de relación entre los vecinos, etc.) y, a la vez, se recupere la noción de comunidad local y de red social, configurando un ambiente más integrador y una referencia para la adscripción socioterritorial de la persona.

Las experiencias de acción comunitaria dirigidas a la infancia y a la adolescencia no pueden hacerse sin la participación activa del centro escolar. Por otra parte, hoy día, la tarea de la escuela no puede ser plenamente satisfactoria sin la colaboración con el resto de la red comunitaria. El trabajo en equipo en los centros escolares, con participación de educadores sociales, puede ser una buena oportunidad para ir caminado en este sentido.

\section{Algunas reflexiones finales}

A lo largo del artículo he ido planteando una serie de cuestiones alrededor de la educación social en el seno de la institución escolar y con esta institución, es decir: en una perspectiva de trabajo conjunto entre el profesorado y los profesionales de la educación social. Se trata de un ámbito de trabajo emergente para educadoras y educadores sociales que ofrece interesantes oportunidades, pero también algunos riesgos.

A título de síntesis, quiero destacar brevemente algunas ideas que me parecen especialmente relevantes en el mencionado contexto de oportunidades frente a riesgos.

- El trabajo en los centros escolares de los profesionales de la educación social supone un nuevo ámbito de intervención - o, en todo caso, su auge- en el cual educadores y educadoras sociales pueden desarrollar funciones distintas. El proceso de concreción de estas funciones y de cómo se incardinan en el conjunto del centro es una cuestión clave: según cuál sea el resultado, según lo que se acuerde, se estará ante una oportunidad para que la institución escolar se adecue mejor a las nuevas realidades sociales o, por el contrario, se reforzará una visión tradicional de la escuela que no es capaz de repensarse a sí misma (esto sí, con la colaboración "técnica" de educadores y educadoras sociales para "apartar" problemas).

- En la relación entre educadores sociales y profesorado se requiere un enfoque global y colaborativo. El enfoque clínico y de experto aísla y transfiere los problemas, en lugar de asumirlos en común, y favorece la segregación del alumnado en lugar de su inclusión. La perspectiva colaborativa es más difícil de conseguir, por lo que se requiere avanzar hacia ella, paso a paso, irla construyendo, solventando las dificultades que con toda probabilidad irán apareciendo. Hay que saber hacia dónde queremos ir y ser pacientes para progresar, dando rodeos si es necesario. - Hay que ir construyendo una visión compartida que sea amplia, global y sistémica. La escuela tiene que abrirse al exterior y contemplar a educandos y educandas en todas sus dimensiones, en lugar de ignorar todo aquello que les sucede fuera del recinto escolar. La entrada de educadoras y educadores sociales puede facilitar esta visión más holística. - En el trabajo conjunto entre profesorado y 
educadores hay que ir construyendo también un concepto compartido de intervención educativa y contemplar que la participación de los profesionales de la educación social también puede ser indirecta, colaborando en el análisis de la práctica y en el diseño de medios, de programas y de situaciones potencialmente educativos.

- La educadora y el educador social pueden ayudar a establecer puentes entre la cultura escolar y las formas y los recursos culturales del territorio y de la comunidad donde se ubica la escuela, siendo probablemente ésta la función que les sea más característica.

- El proceso de apertura de la escuela al exterior puede llevar a la creación y desarrollo de proyectos de acción comunitaria -inicialmente impulsados por los educadores- en los cuales se creen redes y se desenvuelva la corresponsabilidad educativa de la comunidad. La participación de la institución escolar en proyectos comunitarios dirigidos a la infancia y la adolescencia es imprescindible y, a la vez, supone romper con una concepción de escuela encerrada en sí misma para convertirla en una institución que se une a la comunidad en una labor conjunta. Este paso tiene que llegar -en su momento, cuando el proceso esté suficientemente maduro- ya que permite superar algunas de las contradicciones con las que actualmente se encuentra la institución escolar.

Estas consideraciones visualizan la complejidad del proceso de participación de las y los educadores sociales en la institución escolar, pero a la vez presentan este proceso como una oportunidad que debe ir mucho más allá de una simple colaboración técnica. Como todo proceso de calado, requiere su tiempo, pero hay que tener claro hacia dónde queremos encaminarnos.

\section{Referencias bibliográficas}

Cabrera, P. J.: "La vida al raso". Educación Social, 27 (2004), pp. 11-20.

Caride, J. A. (2005): Las fronteras de la Pedagogía Social. Barcelona: Gedisa.

Castel, R.: "De l'indigence à l'exclusion. La desafiliation". En Donzelot, J. (1991): FACE a l'exclusion. Le modèlè français. París: Esprit.

Colegios profesionales de Educación Social (2004): El educador y la educadora social en el Estado español: una concreción de su trabajo en centros escolares.

http://www.eduso.net/ archivos/ESCE.doc

Elboj, C., et al. (2002): Comunidades de aprendizaje. Barcelona: Graó.

Freire, P. (1970): Pedagogía del oprimido. Uruguay: Tierra Nueva [Madrid: Siglo XXI, 1994].

Gasch, B.: "Espais educatius que ofereixen una alternativa al fracàs escolar. Gestió perversa d'un model d'aprenentatge". Educació Social, 32, pp. 61-78.

Giné, N. (2007): Proyecto docente e investigador. Universidad de Barcelona. Documento policopiado.

Llena, A. y Úcar, X.: "Acción comunitaria: miradas y diálogos interdisciplinares e interprofesionales". Úcar, X. y Llena, A. (2006): Miradas y diálogos en torno a la acción comunitaria. Barcelona: Graó, pp. 11-55.

March, M. X. (2007): "La educación social en el marco de la construcción del Espacio Europeo de Educación Superior". Pedagogía Social, 14, $3^{\text {a }}$ época, pp. 33-52.

Morgenstern, S.: "El reparto del trabajo y el reparto de la educación". Varios (1995): Volver a pensar la educación, vol. 1. La Coruña-Madrid: Fundación Paidea-Morata, pp. 329-341.

Molina, J. G. y Blázquez, A.: "El educador social en la educación secundaria". Educación Social, 32 (2006), pp. 39-58.

Ortega, J.: "La educación a lo largo de la vida: la educación social, la educación escolar, la educación continua... todas son educaciones formales". Revista de Educación, 333 (2005), pp. 167-175.

Pallisera, M. (1996): Intervención educativa en el campo de las disminuciones. Proyecto Docente. Universitat de Girona (documento policopiado). 
Parcerisa, A. (1999): Didáctica en la educación social. Barcelona: Graó.

Pérez Serrano, G. (2003): Pedagogía social-educación social. Construcción científica e intervención práctica. Madrid: Narcea.

Petrus, A.: "L'educació social al llindar del segle XXI”. Temps d'Educació, 15 (1996), pp. 13-37.

Petrus, A.: "Nuevos ámbitos en educación social". Romans, M.; Petrus, A. y Trilla, J. (2000): De profesión: educador (a) social. Barcelona: Paidós, pp. 63-147.

Riera, J. (1998): Concepto, formación y profesionalización de: el educador social, el trabajador social y el pedagogo social. Valencia: Nau Llibres.

Schön, D. A. (1983): The Reflective Practitioner: How Professional Think in Action. Londres: Temple Smith.

Trilla, J.: "L «Aire de Família» de la pedagogia social”. Temps d'Educació, 15 (1996), pp. 39-57.

Trilla, J.: "El universo de la educación social". Romans, M.; Petrus, A. y Trilla, J. (2000): De profesión: educador (a) social. Barcelona: Paidós, pp. 15-59.

\section{Notas}

${ }^{1}$ Posteriormente, el autor publicó una nueva versión en: Trilla, 2000.

2 Petrus (2000) señala algunos de los ámbitos emergentes en educación social: el conflicto y la violencia, la tercera edad y el deporte como factor de socialización.

${ }^{3}$ La información sobre experiencias de introducción de educadores y educadoras sociales en los centros escolares puede ampliarse en: Colegios profesionales de educación social (2004).

${ }_{4}$ Para información sobre las experiencias de comunidades de aprendizaje puede consultarse: Elboj et al. (2002).

${ }^{5}$ Es evidente que entre los centros escolares existe una gran diversidad y que parte de ellos se han abierto a la comunidad y trabajan con planteamientos semejantes -en el fondo- a aquellos que son más característicos de la educación social. En el artículo se hace referencia a cuando no es este el caso y precisamente se apunta que no se trata de que educadores y educadoras sociales enseñen al profesorado, sino de que se aprenda mutuamente, de que se construya en común aprovechando la diversidad de miradas, y de que sea el propio centro escolar quien asuma planteamientos de formación integral, de visiones holísticas y de interrelación con la comunidad, en lugar de resignarse a seguir con la cultura académica más tradicional dejando para otros las funciones compensadoras.

DiReCCIÓN DEL AUTOR: Artur Parcerisa Aran. Universidad de Barcelona. Vicerrectorado de Política Docente. Gran Vía de les Corts Catalanes, 585. ○8007 Barcelona.

Correo electrónico: artur.parcerisa@ub.edu

Fecha de recepción del artículo: 14.XI.2007 Fecha de aceptación definitiva: 13.XII.2007 
